\title{
Creativity Exercise: Connecting Disparate Products, Services, or Concepts
}

\author{
Dan Holland (Utah State University)
}

KEYWORDS: Entrepreneurship, Teaching Methods, Higher Education.

This classroom exercise encourages students to practice connecting concepts, products or services that they would not normally consider combining. It is a straightforward and stimulating exercise intended to provide students with a greater understanding that many innovations result from the intersection of disparate concepts or fields. The exercise also demonstrates the value of working with others and purposeful effort in generating ideas.

Keywords: Ideation, combination, recombination, intersection

\section{Subject Area: Ideation}

Student Level: Any level

Type of Course: Entrepreneurship course with a module on idea generation and discovery.

Time Required: $30-45$ minutes

Recommended Number of Students: Any number of students. Students will work in teams of 2 or 3

\section{Learning Objectives}

Definitions of creativity often refer to new combinations of existing ideas, concepts, fields or items to create something novel and useful (McCrae \& Ingraham, 1987; Perry-Smith \& Manucci, 2015). Innovators are skilled at working with others to combine and tweak different technologies or attributes into new products, services or processes (see Hargadon, 2003; Arthur, 2009). It has been argued that creativity may increase when an individual is frequently exposed to unusual combinations of objects or people, encouraging novel interconnections (Epstein et al., 2008).

This classroom exercise provides students with the opportunity to experience and reflect on the potential of making new combinations, in a brief but meaningful

way. The learning objectives for the exercise include:

- Understand the link between creativity and making new combinations and intersections

- Break down creative barriers by experiencing the discomfort that is often associated with combining disparate ideas or objects

- Experience the satisfaction that results by forming a creative combination that had not previously been considered

- Reflect on how to foster an environment conducive to combinations

\section{How it Works}

I use this exercise as one of several creativity exercises during an introductory entrepreneurship course. Students are required to complete an idea journal with many new potential ideas. They are given a set of techniques that may be used to generate ideas, of which this is one option. I introduce the creativity techniques after a foundational discussion of creativity and breaking down creative barriers (see Appendix 1 for a small sample of content related to this exercise). The basic elements of this connections exercise are as follows:

- Students are formed into teams of two, or three if there is an odd number.

- Each participant independently makes a list of 10 - 15 products and services. These items may be any random product or service, but it is preferable if the students include several products or services for which they have some passion or interest. It is often more meaningful to generate new ideas about products or services that they care about.

- Each pair is expected to work together to combine items from one list with items from the other person's list and see if they can develop a new or improved product or service from the 
combination.

- Students should consider many different combinations from the lists and push themselves to work through several iterations of combining concepts loosely related to the items. For example, they should let their mind wander if their discussion of a combination sparks any kind of idea, even if it not obviously related to the initial list items.

- You may choose to have students start by writing down their own potential combinations before conversing with their partner. That gives them time to brainstorm their own ideas without influence from the partner.

Before starting the exercise, it is important to emphasize that the goal is NOT to create new compound words but to create new combinations that may result in genuine opportunities. This is a common tendency for the students, if you do not address it. For example, if one person has "shoe" on her list and another has "phone" on his list, an obvious combination would be a "shoephone." That is fantastic for Maxwell Smart (see Get Smart), however, there is much more potential value in taking the combination to a deeper level. For instance, one might think of the properties in a shoe that provide protection, support, and breathability and try to think of ways to apply that technology to a phone case. Or perhaps the team might consider a phone app that allows a person to take a picture of a stranger's pair of shoes, searches a database to match the picture, and connects to a store for easy online ordering. Or the students might consider the purpose of the items and combine concepts - e.g. phones are communication devices and shoes are a basic tool in transportation. What might we learn from communication that can be applied to transportation, or vice versa?

During the exercise, the teacher should roam the room and work with pairs of students who seem to be "stuck" on a combination to help them move forward with new possibilities. You may need to provide more structure by giving students a short list of questions or prompts to help them flesh out an opportunity associated with one of these combinations? For example, you could ask them to articulate a preliminary value proposition or an initial target market that will give them greater direction and focus in their combinations.

After the students have had about 20 - 30 minutes to work on several combinations, it is useful to move to a broader class discussion. The teacher may ask a few groups to share their ideas and track the path that they followed to get to that idea. Then, as a class, the instructor may choose to build on one or two of the ideas to consider several more combinations, with the larger group. This may help students experience new ways to approach the combinations.

Typically, 30 - 45 minutes should be allowed for the inclass portion of this exercise, including discussion. However, the exercise may be shortened or lengthened. The learning process is most effective when the students are required to continue the process outside of class with a homework assignment with clear deliverables, including reflection. For example, the students may be expected to:

- Document the original list and the partner's list.

- Share at least 5 basic combinations that were considered.

- For two or three of the combinations, go well beyond the original combination. Share the path of discussion that was taken to reach a potential new product or service idea.

- Explain why the resulting product or service ideas have potential value.

- Search for three current products or services in the marketplace that appear to be

- combinations of previous products or services.

- Reflect about the experience and process. What creative barriers were experienced? How did forcing connections break down barriers? How might an individual increase awareness of and the propensity to consider combinations of disparate products, services, or concepts regularly.

It is important to note that the most valuable outcome of this exercise is not the resulting ideas, although they are sometimes quite interesting, but rather the realization of the creative potential of connecting concepts from one product, service, or industry to a seemingly unrelated product, service, or industry. It should be emphasized that creative connections will become more likely if we proactively acquire new knowledge from diverse fields, expand our network to include people with different backgrounds and expertise, and practice connecting ideas.

\section{Student Feedback}

I have not tested the effectiveness of this individual 
exercise in increasing creativity. However, I regularly test the impact that the whole set of creativity techniques, of which this is one, has on the students' ability to generate a greater number and a higher quality of ideas. After learning and practicing the various creativity techniques, the data consistently shows that students significantly increase their ability to generate higher quantity and quality of ideas at end of the semester versus the beginning. I do not include the method and measurements here, since it is not specific to this technique, but I invite you to contact me for more information, if desired. Regarding this specific exercise, I include a small sample of comments from students to demonstrate some of the learning that may happen from the exercise. These reactions are extracts from students' reflections about working through the exercise.

"Performing the exercise was an enjoyable experience. Some of the generated ideas were wacky and completely impractical, while others did have some value. This process allowed you to bounce ideas back and forth within a team. Sometimes a teammate would see a different view of a combination and in turn would find a hidden value." (Michael C.)

"One of the techniques that worked well for me was the forced combinations. When I had a list of items (or ideas) to compare against one another and draw conclusions, my mind was better able to generate ideas around two separate things that from the surface are not related at all. This is exactly what my mind needed - direction. So, oddly enough from this technique I discovered that one of my biggest barriers to creativity is actually not having any barriers (constraints) at all." (Colby B.)

"The technique that worked really well was the forced combinations. At first I thought it was a cheesy archaic method for idea generation but upon application doors blew off their hinges. I think this one worked so well for me because it was more concrete than abstract or theoretical." (Cord P.)

"The technique that I found most frustrating was forced combinations. Luckily for me I had a great partner and she was able to help a lot. There was just a crazy block in my brain that couldn't create something out of two random objects." (Shane $S$.)

\section{References}

Arthur, W. B. (2009). The nature of technology: What it is and how it evolves. New York: Free Press. Epstein, R., Schmidt, S.M. \& Warfel, R. (2008) Measuring and Training Creativity Competencies: Validation of a New Test, Creativity Research Journal, 20:1, 7-12,

Hargadon, A. (2003). How Breakthroughs Happen: The Surprising Truth About How Companies Innovate. Boston: Harvard Business Review Press.

McCrae, R. R., \& Ingraham, L. J. (1987). Creativity, divergent thinking, and openness to experience. Journal of Personality and Social Psychology, 52(6), 1258-1265.

Michalko, M. (2006). Thinkertoys: A handbook of creative-thinking techniques. Berkeley: Ten Speed Press.

Perry-Smith, J \& Mannucci, P.V. (2015). From creativity to innovation: the social network drivers of the four phases of the idea journey. Academy of Management Review, 42, pp. 59-79

Seelig, T. L. (2012). InGenius: A crash course on creativity. New York: HarperOne.

Author's Note: I would like to thank the reviewers for their meaningful suggestions that have helped to improve this article.

\section{Appendix 1: Note to Instructors}

There are many examples of creative products and services that are new combinations or are influenced by other fields or concepts. It is helpful to share some of these examples so that students can see the relevance of the skill. A few examples that you might consider include:

- The story behind the creation of Play-doh (see $\mathrm{h}$ ttp://ecorner.stanford.edu/videos/1187/What-IsCreativity )

- Steve Jobs discussion of the influence of calligraphy on his design of the Mac (see http://n ews.stanford.edu/2005/06/14/jobs-061505/ )

- The Medici Effect by Frans Johansson discusses many types of combinations or intersections that have resulted in business innovations.

Other resources that I have discovered that offer 
independently developed exercises that are very similar to this include InGenius by Tina Seelig (pg. 37) and Thinkertoys by Michael Michalko (pg. 332). Their perspectives have been helpful in refining this exercise and may provide additional value to any instructor considering this exercise.

\section{Read More}

Why Didn't I Think of That? A Classroom Exercise for Developing Entrepreneurial Thinking (https://eiexchange.com/content/32-why-didnt-i-think-ofthat-a-classroom-exercise-

f?search=Why\%20didnt\%20l\%20think)

'Becoming DaVinci' Exercise Ignites the Inventor Spirit (https://eiexchange.com/content/306-becoming-da-vinci -exercise-ignites-the-

inventor-?search=becoming\%20davinci)

Creativity: How to Nurture it and Get it Back (https://eiexchange.com/content/114-creativity-how-to-n urture-it-and-get-it-

back? search=creativity\%20how\%20to\%20nurture)

Additional Search Terms: finding my creativity, encouraging creativity, finding good ideas, getting a business idea 